\title{
An Awakening (Part I)
}

BY ROBERT J. FELLER

\begin{abstract}
Science can be introduced to children well or poorly. If poorly, children can be
turned away from science; they can develop a lifelong antipathy; they will be

in a far worse condition than if they had never been introduced to science at all.
\end{abstract}

Isaac Asimov

MY PURPOSE in this article is to increase awareness about long-standing problems in science education and then, in Part II, to build a case for how marine scientists, and scientists in general, can help improve science teaching and learning at all educational levels. What follows relates a personal journey, started 11 years ago when a former undergraduate who had worked in my research lab convinced me that there was a better way to teach the laboratory portion of our introductory marine science course than by simply lecturing. I was initially quite reluctant to delve into the world of science education, because I didn't think that pedagogy was anywhere near as important as the straight delivery of solid content knowledge (= lecture). After all, that's how I learned science, and if it worked for me, then it should work for other students!

Having completed her master's

\section{Robert J. Feller (feller@biol.sc.edu)} is Professor, Marine Science Program and Department of Biological Sciences, and Director, Center for Science Education, University of South Carolina, Columbia, SC, USA. research, this former student needed me to help her negotiate the bureaucratic maze and mixture of two different cultures she would encounter during her Ph.D. committee interactions with colleagues from the mysterious College of Education and our own (at the time) College of Science and Mathematicsthus began my awakening. I have continued interacting with these education professionals, most recently while providing content-rich, inquiry-based professional development to elementary, middle, and high school science teachers during the last four years. Other facets relevant to the current state of science teacher preparedness and student learning have become evident through my advisement activities and teaching that involves both prospective (pre-service) science teachers in our Master of Arts in Teaching and in-service (practicing), certified science teachers in our Interdisciplinary Master of Arts degree programs. As I continue this journey, I realize daily that this awakening is a work in progress.

I began my teaching and research career in oceanography as a graduate student in 1970 at the University of
Washington almost 40 years ago (wow, I've been married even longer than that!). If you are at all like me, you've probably been teaching your particular science discipline in the same way it was taught to you-using the classical lecture format. You also probably gripe to your colleagues about the poor classroom performance of undergraduates in your classes. I also would bet that you have but little time to devote to teaching because it is more rewarding and important that you pursue grants, generate indirect cost recovery, and bring credit to your home institution by publishing your research results in the most prestigious journals possible, not to mention all those additional service obligations. Such activities are time-consuming, I know, but being a busy scientist also means that you may be wearing blinders that block awareness about the state of affairs in local schools that send students (yes, the ones you gripe about) to your introductory science classes. I was certainly wearing them. Maybe you are just too busy doing research to express concern about it. Even if you have school-age children, how much time have you spent getting to know their science teachers? It is time 
to remove your "bench science" blinders and take a look at some critical concerns that I have about science educationthat's right, SCIENCE EDUCATION. Let's reminisce a bit first...

How did you get interested in science? You probably had supportive, inquisitive parents and at least one teacher who opened the floodgates of your imagination and curiosity — what grade were you in when this happened? I would guess you got interested in science not only because of an influential teacher, but also because you were pretty good at math. You probably were comfortable thinking graphically or at least three dimensionally, though this particular skill can be honed later in life. Regardless, your exposure to these critical areas in scientific literacy began at an early age whether you were aware of it or not-fun trips to the zoo, gazing at the star-filled sky, helping fix the car or lawnmower, catching that first fish, finally beating your older sibling or a parent in a game of checkers, watching a savings account grow (or not!), walking through the woods, seeing the ocean (or snow) for the first time, caring for a pet, and maybe even viewing death. All such events shape us, some more than others. How many such experiences did you have at school?

Once hooked by one's own curiosity and wonderment at how nature works, we typically breeze through the latter stages of the K-20 educational experience into graduate degree programs and never look back because, no matter the discipline, every question posed always raises more questions - the more you learn, the more you want to learn. It is intoxicating and even addictive. Pragmatically, however, to practice "science," most of us have had to align with some sort of academic institution through which applications for funding could be made. Strangely enough, besides serving as a platform for supporting your scientific endeavors, these places also exist because they are where a lot of teaching happens. Unfortunately, I know I am not the only one who senses this, but these places are also where a lot less learning seems to be taking place these days.

I teach at a large state-located (formerly state-funded or state-supported) university servicing tens of thousands of students. All undergrads here must take seven or eight science credits, with at least one lab; science majors must take much more, of course. I get the sense that a lot of them (including science majors) would rather watch DVDs, play video games, sleep, surf the net, text message, tailgate, and party rather than be a front row student. That old, comfortable Age of Aquarius is long goneit's now the Age of Entitlement- "Dear professor, you should be grateful that I'm here in your class today because it costs like a lot of money to be here, like, there are so many other things I'd really, like, rather be doing. That makes me worthy of, like, getting an A, right?" Worthy yes, entitled, no! It makes you want to scream sometimes. Thank goodness there is a filter-the lower end of a normal grade distribution. I used to think science is simply not for everyone, but now I wonder how many potential scientists have simply been turned off by having less-than-stimulating science teachers. Why does this happen? How many are turned away (see Asimov quote above)? Or do scientists become scientists despite having weak science instruction in their early, formative years?

I began a decade ago to interact more and more with colleagues in the College of Education-you know, that dark, mysterious place on the other side of campus well-known to harbor faculty who are passionate about teaching (just as passionate as we are about research) but who know nothing about doing "real" research. Real research, mind you, resides exclusively in colleges of science and mathematics, not education! Most of us view these education-oriented colleagues as pedagogy wonks, while we are known to them as "bench" scientists. Remember the stereotypical pictures of scientists that children draw-Einsteinesque white males in white lab coats wearing glasses and holding test tubes? That fun movie "Back to the Future" comes to mind as well, so it is not just young children who characterize us that way. What an incredible wall we have erected between these two academic cultures, a wall built with bricks of misinformation cemented with misconceptions and surrounded by a moat modestly full of disdain. What a shame we don't appreciate each other more.

My appointment in 2003 as director of the Center for Science Education included the charge to drain this anachronistic moat or to at least construct a footbridge across it. Unfortunately, a narrow swinging rope footbridge will probably suffice, because the line of faculty waiting to cross in either direction is quite short. We ought to be building a high-volume rapid transit system across this gap because, if we don't, the foundations upon which scientific discovery thrives may soon wither and die. From what I have learned these past four summers working with life, physical, 
and earth science teachers, the seeds for growing new scientists and mathematicians are being planted and watered much too infrequently.

My science education colleagues in the College of Education have an amazing zeal for reforming how we teach science. Their enthusiasm is a necessary but insufficient ingredient for addressing this enormous task. Practicing scientists are equally enthusiastic about conducting research, but their interest in getting more students and lay people involved is constrained or dimmed by the lack of time available for this type of outreach activity. Needless to say, the research university reward system is also highly skewed against it. Because the reward system in higher education is not likely to be reversed or resolved in the remainder of my lifetime, it will not be revisited here. Instead, I will focus on some scientific literacy issues that ultimately impact the quality of the students who populate our introductory science classes. I believe that higher-ed science faculty not only have a societal responsibility to address the issues but also have a vested interest in doing so, despite the initial discomfort and awkwardness that can occur when pedagogical wonks and bench scientists meet on common ground with a single purpose-to improve science education. Somehow, I just don't see politicians solving the global-scale environmental problems that now exist. We need more well-trained scientists-period.

Below, I list a few of the things that have contributed to my awakening about the state of science education in the United States. They are based on my personal observations, conversations, professional development sessions, experiences with missed learning opportunities, and classroom visits with teachers, predominantly in South Carolina, but elsewhere as well. There are exceptions, of course, and not all science teachers will fit each point. Thankfully, a majority of our nation's science teachers have persisted in the face of challenges and obstacles that would defeat the best among us. My hat is off to them.

\section{SOME CHARACTERISTICS OF TYPICAL SCIENCE TEACHERS}

1. They enjoy nurturing the natural curiosity of students and helping them learn and grow but are constrained in their attempts to do this.

2. These teachers are largely on their own in the classroom, have little collegial support, and feel isolated most of the time.

3. They have little opportunity for participating in meaningful growth of their teaching strategies through professional development; hence, they rely on tried-and-true lessons and strategies they have used before, moving back to their comfort zones.

4. They often feel swamped by No Child Left Behind mandates for accountability, seemingly endless paperwork, record-keeping requirements, and high-stakes testing.

5. Their lesson plans are supposed to conform with state science standards/indicators.

6. They too often view standards/indicators as being the learning objectives (i.e., they consider them what students must know versus simply using them as guides to essential information and concepts related to the standards); this quite possibly results from lack of deeper content knowledge about many of the standards.

7. Most are exhausted by the end of the school day; many teach from 75-150 students every two days each semester (remember this as a multiplier!).

8. They do not routinely read scientific literature to keep abreast of new discoveries.

9. They will participate in additional, nonmandatory professional development if paid a stipend (justified if outside normal working hours), but are less interested even if it's provided free of charge.

10. They use technology if available (impossible in poor schools), but seldom seek it out and rely more on use of computer labs as opposed to in-class technology; reliability of the technology is always an issue as are district-imposed firewalls/internet content blockages.

11. Their initial motivation to seek national certification is primarily to achieve a pay boost and increased status, only secondarily to gain a reflective means to improve their teaching performance. 
12. They have little time or energy for extracurricular learning opportunities during the school year; late afternoons and weekends are the only possible times for this, but family needs compete heavily with such demands on their time.

13. Necessary teaching supplies and equipment are often lacking, but they are hesitant to pursue outside funding due to lack of grant writing skills and/or time to write grants.

14. These teachers are vastly underappreciated by the public and are grossly underpaid in most school districts.

15. Holidays/time off from teaching is absolutely necessary for rejuvenation.

\section{ELEMENTARY SCHOOL SCIENCE TEACHERS}

(Learning about science is fun!)

1. May have little to no formal science training and took only minimal science classes

2. May be teaching not just science but also language arts and other content areas

3. May have too little time to teach science, as other content areas are tested more

4. May view science as a collection of factual information rather than as a process

5. Do not fully understand the nature of science as a way of knowing

6. Inadvertently and unintentionally pass on misconceptions about science

7. Think more qualitatively than quantitatively and may be math phobic and lack graphing skills

8. Do not read scientific journals but enjoy TV "science" (Discovery Channel, National Geographic, especially Shark Week, or popular science magazines

\section{MIDDLE SCHOOL SCIENCE TEACHERS}

(Hey, kids, learning about science is cool, but it's not easy. It takes a lot of work!)

1. Are most attracted to this grade level because the students are at such an interesting stage of development and personal growth

2. Have wide gaps in science and math content knowledge

3. Seldom read journals, also love TV "science" and lay science publications

4. Do not integrate math into their science lessons either because of math anxiety or because their math-teaching colleagues view math as THEIR province-some actually state that their math department colleagues expressly ask that they NOT use math in science because math is what THEY are supposed to teach!

5. Are strongly dependent upon their classroom textbooks for content and are unaware of whether the content is good, bad, or otherwise

6. Rely heavily on the Internet, specifically Google, for subject matter information but may have difficulty judging a source's reliability/quality

7. May equate having students use science process skills (e.g., measuring, weighing, observing, counting, inferring, classifying) with practicing inquiry skills or learning science as a way of knowing

8. Seldom interact with higher education faculty

9. Need additional technology training

10. Have little time for meaningful discussions about science with their colleagues or for learning new pedagogical strategies with their peers (need release time to do this)

11. Are very well-organized, task-oriented, and have excellent classroom management skills

12. Have only modest academic interactions with parents of their students, usually regarding issues related to discipline or problems with students being off task

13. Are forced to focus on testing and standards and often teach to the test, thus stifling open-ended classroom activities during which students can explore, be curious, and actually practice using inquiry 
14. Are highly motivated to keep students busy with activities during class, no matter whether the activity has strong educational value

15. Unknowingly pass on their own misconceptions about science to their students

16. Hold elementary teachers accountable for their students' inadequacies in science

\section{HIGH SCHOOL SCIENCE TEACHERS}

(Science is complicated and challenging!)

1. Are more likely to interact with higher education faculty, but reluctant to appear uninformed-typically ask questions seeking clarification/confirmation

2. Have adequate content knowledge in their area of specialization (e.g., biology, physics, chemistry) but often are challenged by top students-need deeper content knowledge

3. Mostly teach the way they were taught-lecture, PowerPoint

4. Have major misconceptions about the nature of science/process of scientific discovery

5. Often have classroom management/control issues that impede learning in their general classes (vs. AP or advanced classes)

6. Must frequently adapt to situations that change dynamically (e.g., missing/broken lab equipment, instrument failure, technology glitches)

7. Have knowledge gaps in experimental design and anxiety about data analysis and the purposeful use of statistics in hypothesis testing

8. Seldom use technology in the classroom - technology (instrumentation) is mostly used in the science lab, not the classroom

9. Blame middle school teachers for their students' content shortcomings in science (Note: Higher-ed faculty mostly blame high school teachers for this and do not realize that misconceptions about science can start as early as the second or third grade.)

In Part II, I will make some suggestions about how to help science teachers learn more about science and how they and your College of Education colleagues can help scientists become better teachers. The next grant application you write will have space for educational outreach-in fact, it's mandatory. Your science education colleagues on campus across the street or at that other college down the road can make wonderful partners for designing programs that will engage and help both science teachers and their students. Take your pick of problemseverything listed above is fair game. You can help and, if you do, perhaps my awakening can be a shared experience.

\section{ACKNOWLEDGEMENTS}

I thank Elizabeth Day-Miller for stimulating my awakening to science education at the formal research level. Jon Singer introduced me to the world of Professional Development at the middle school level and to the effective use of technology in the classroom. Christine Lotter has encouraged and promoted my delivery of deeper content during summer professional development programs for high school science teachers. Lastly, my thanks to a very level-headed friend, John Carpenter (Distinguished Professor Emeritus, Dept. of Geological Sciences), who promoted my appointment as the fourth Director of USC's Center for
Science Education. I also thank the dozens of schoolteachers who have graciously shared their needs and their passion for teaching with me. Oh, and let us not forget my daughter's fifth grade science teacher, source of the misconception that saltwater does not conduct electricity (Feller, 2007) - may she never venture out to sea in a thunderstorm! This is Contribution No. 1476 from the Belle W. Baruch Institute for Marine \& Coastal Studies. 四

\section{REFERENCES}

Feller, R.J. 2007. 110 Misconceptions About the Ocean. Oceanography 20(4):170-173. 